\title{
Application of Google Earth for flood disaster monitoring in 3D-GIS
}

\author{
M. Mori \& Y. L. Chan \\ Department of Information and Computer Science, \\ Kinki University, Japan
}

\begin{abstract}
A prototype flood monitoring system has been developed using Google Earth related to Geographic Information Systems (GIS). GIS have become effective tools for analyzing flood disasters, especially for three-dimensional (3D) analysis. However, high performance commercial GIS are very expensive so many offices, such as the U.S. National Weather Service (NWS), use web-based flood monitoring systems such as Google Earth. A web-based monitoring system is a low cost and efficient means to monitor local occurrences of floods. The present monitoring system is designed to provide the output result via a webbased interface to agencies, in both the public and private sectors. The present system provides estimated inundation zones, water depth, and flood hazard map via a web-based interface, which are based on a two-meter Digital Surface Model (DSM). A $2 \mathrm{~m}$ DSM is a more precise 3D model when compared with the previous Digital Elevation Models (DEM).
\end{abstract}

Keywords: flood, Google Earth, 3D GIS, DEM/DSM.

\section{Introduction}

Flood damage is quite severe in northern Kyushu, Japan, during the yearly typhoon season. Floods are most frequent, making up $46 \%$ of all natural disasters and cause most human loss, affecting $78 \%$ of the population who have experienced natural disasters [1].

A prototype web-based flood monitoring system has been developed, which uses Google Earth pro v.5. Google Earth pro is more advanced than the standard version, which enables easy connection with not only Key-hole Markup Language (KML) files but also GIS files. 
Google Earth pro allows high-resolution imagery to be combined with varied types of information, including GIS data. The most important input data is elevation data for the present flood monitoring system [2].

The present flood monitoring system is designed to meet the needs of agencies, in both the public and private sectors, and local governments are especially important for predicting and monitoring flood occurrences in their jurisdiction. However, GIS software such as ArcGIS may not be available to local governments, in which case KML files are quite useful for monitoring the output result using a Google Earth viewer.

For this research report, ArcGIS 9.3 (ESRI) and Google Earth pro v.5 are mainly used as a GIS analysis system and a viewer for PC Windows.

\section{Flood monitoring system}

\subsection{Digital Elevation Model and input data}

Several GIS data, such as static geospatial data, are necessary for flood monitoring systems. Digital Elevation Models (DEM) are quite important in generating a three-dimensional topographic map to enable flood risk assessment of damages. 3D GIS require DEM for analysis, which can construct a surface model around flood disasters. So far, a $50 \mathrm{~m}$-meshed DEM developed by the Geological Survey of Japan (GSJ) is widely used for various GIS applications such as constructing 3D systems to create three-dimensional representations of the land in Japan. However the $50 \mathrm{~m}$ DEM is insufficiently accurate, making a higher-resolution DEM necessary. Then a 2 meter Digital Surface Model (DSM) was used for generating contour lines in the present system. A commercial company has recently developed a high-resolution DSM of up to 2 meter horizontal resolution meshed. A $2 \mathrm{~m}$ DSM is quite effective for various applications with GIS, having enough resolution to distinguish individual houses.

Also several digital maps such as ward boundary line data and road line data based on a 1:2500 digital topographic map from the Geographical Survey Institute (GSI) of Japan are used for data integration. The Google Earth viewer shows natural images of the geode, which do not include city boundary lines. Ward boundary lines are quite important to local governments when issuing flood alerts to the residents.

Rainfall rates and accumulations are available in $17 \mathrm{~km}$ squares by Automated Meteorological Data Acquisition System (AMeDAS) used by the Japan Meteorological Agency, which are updated every 10 minutes. Aerial photography with high spatial resolution of $0.25-0.5 \mathrm{~m}$ is used instead of lowresolution Google Earth images due to the granularity of the images in some regions.

\subsection{Processing GIS data}

The coordinates used in Google Earth are only approximate because it is merely a viewing tool for obtaining a general idea of the cache location rather than for 
technical application such as ArcGIS, and the errors in position can be as much as $30 \mathrm{~m}$. Thus it is necessary to correct the coordinates. The difference around the Onga River, the study area is found to be $14.64 \mathrm{~m}$. Before processing GIS data, it must all be corrected to the Google Earth coordinates.

After geometric correction, precise contour lines are necessary for generating a 3-dimensional model of the region by $2 \mathrm{~m}$ DSM using 3D analysis in ArcGIS. A KML file for Google Earth is created by ArcGIS or Google SketchUP from GIS data.

\subsection{Output results}

One output result of the present monitoring system is inundation zone maps, which are estimated from $2 \mathrm{~m}$ DSM depending on rainfall rates and accumulations. Inundation zone images are shown with color-graded danger levels. Figure 1 shows a sample Google Earth image around the Onga River in northern Kyushu, Japan, and Figure 2 shows an estimated inundation zone of Figure 1 overlaid with a Google Earth image. Heavy rainfall occurred in northern Kyushu on July 19, 2003 [3]. As a result of the storms, the Onga River burst its banks, and the flood waters reached the central part of Iizuka City.

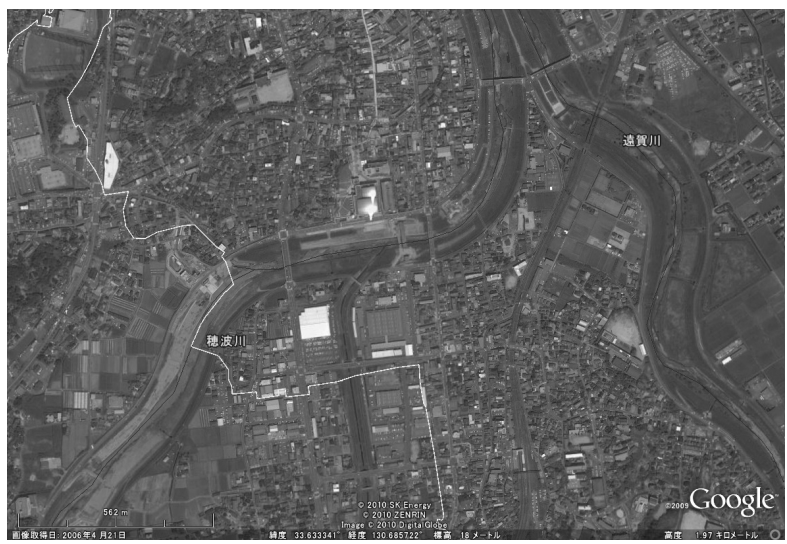

Figure 1: Google Earth image around the Onga River.

Also, the water depth of the river is calculated from the $2 \mathrm{~m} \mathrm{DSM}$ and a topographic map to estimate the water flow in the river. Figure 3 shows a sample of the same region of the river in Fig. 2 overlaid with a Google Earth image.

Ward area maps in Iizuka City in northern Kyushu are shown in Fig. 4 overlaid with Google Earth images. Ward area maps are important for flood alerts.

Figure 5 shows a 3D view of a small hill overlaid with a Google Earth image, the $3 \mathrm{D}$ model of which is based on a $2 \mathrm{~m} \mathrm{DSM}[4,5]$. 


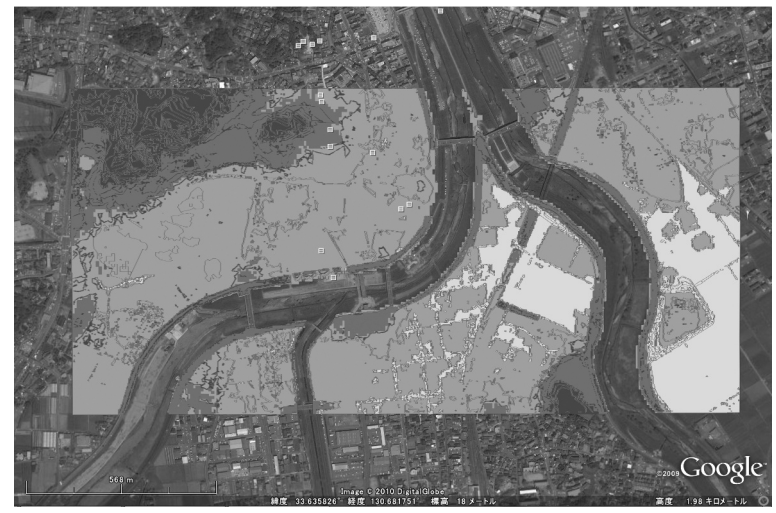

Figure 2: $\quad$ Estimated inundation zone of the Onga River.

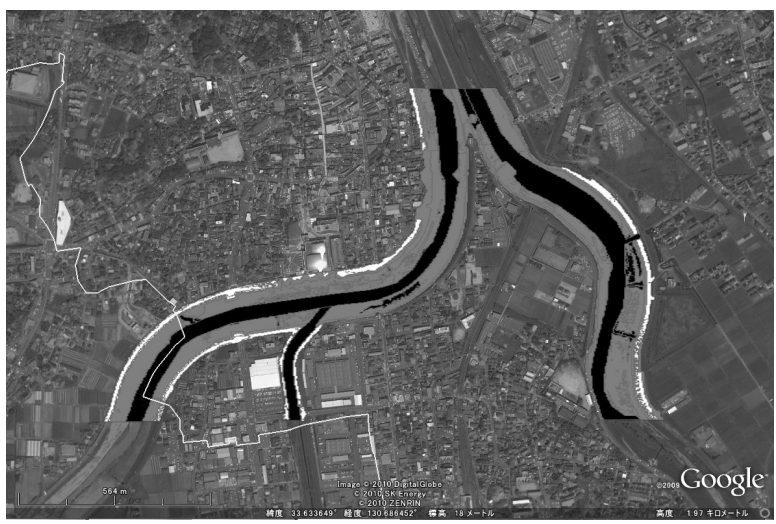

Figure 3: $\quad$ Water depth of the Onga River.

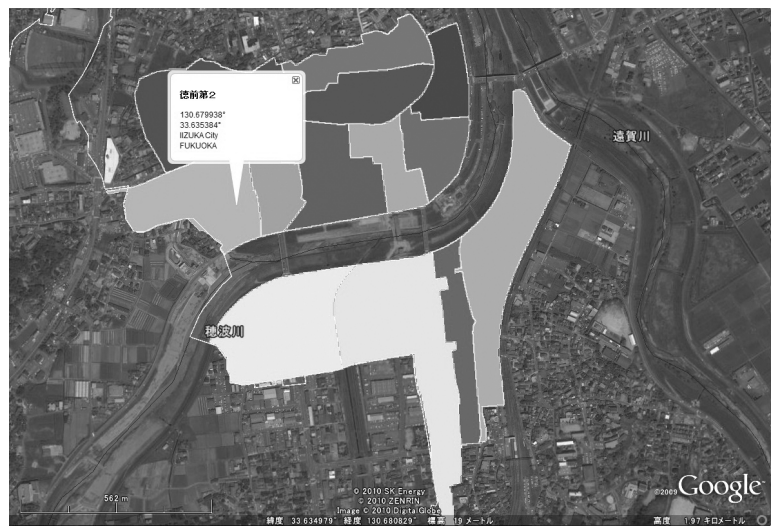

Figure 4: Ward area maps in Iizuka City, with additional information available by clicking. 


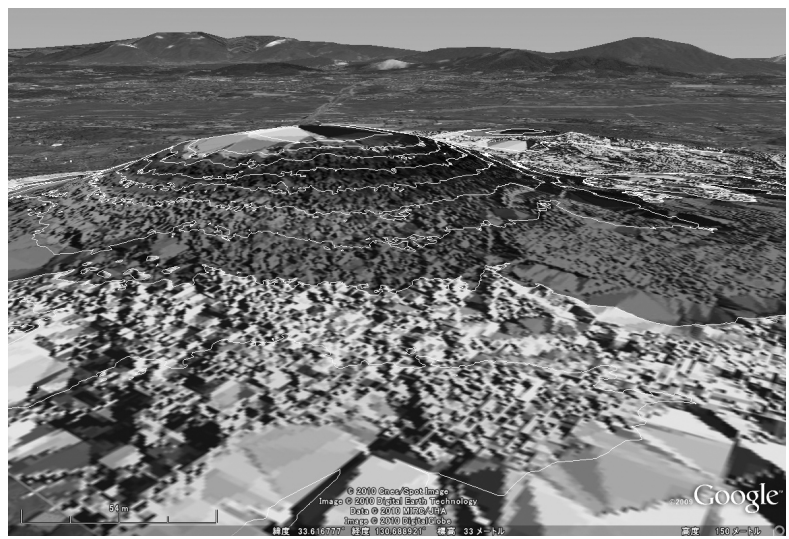

Figure 5: $\quad 3 \mathrm{D}$ view of a small hill with contour lines.

\section{Data delivery system}

The present monitoring system is designed to provide the output result via a web-based interface to agencies, in both the public and private sectors. The type of output data are various, including GIS files (shapefile), KML files, and images. KML formatted files are most useful since they are used in the Google Earth viewer to display results without the need for any GIS software, and are a quite low-cost system.

Advanced users of GIS software such as ArcGIS by ESRI can use shape files to monitor results, and can also analyze them according to their technology and purpose. Shape files are available via ftp.

\section{Conclusions}

A prototype web-based flood monitoring system has been developed using $2 \mathrm{~m}$ DSM, which is designed to provide the output result. The most useful output result may be a KML file for Google Earth viewer. However, the present flood monitoring system does not include a physics-based hydrological model due to the simple system requirements. A physics-based hydrological model needs more precise rainfall rates and accumulations. The next model of the present system being considered is to include a physics-based hydrological model.

The update rate of data delivery is quite important for practical uses, especially in the public sectors for issuing sudden flash flood alerts. The output data of the present system is not updated periodically because it cannot automatically process data from AMeDAS. 


\section{Acknowledgement}

The present work was partially supported by the Grant-in-Aid for Scientific Research (C) No.16510141 of the Ministry of Education, Science and Culture of Japan.

\section{References}

[1] Groeve, T.D., et al., Near Real Time Flood Alerting for the Global Disaster Alert and Coordination System. Proceedings of ISCRAM, pp.33-39, 2007.

[2] Green, T.A., et al., Anticipating urban flash flooding using basin upstream rainfall (BUR) and Google Earth. 34th Conference on Radar Meteorology, P14.3, 2009.

[3] Ushiyama, M., Characteristics of heavy rainfall disaster in Kyushu district from July 19 to 21, 2003. Journal of Japan Society for Natural Disaster Science, 22(4), pp.373-385, 2004.

[4] Anupam, K.S., GIS and a remote sensing based approach for urban floodplain mapping for the Tapi catchment, India. Proc. of Symposium JS.4 at the Joint IAHS \& IAH Convention, Hyderabad, pp.389-394, 2009.

[5] Yamada, Y., Morphological analysis of flood inundated region in Paddy areas using ALOS/PALSAR data and its distribution on the Google Earth design of the future disaster management system (FDMS). The International Archives of the Photogrammetry, Remote Sensing and Spatial Information Sciences, Vol.XXXVII, Part B4, pp.1117-1121, 2008. 